\title{
Safety Culture Maturity in Several Latin America Mining Activities
}

\author{
Marc Bascompta, Lluís Sanmiquel, Josep Oliva, Hernán F. Anticoi, Eduard Guasch \\ Iberpotash Chair in Sustainable Mining. ${ }^{2}$ Department of Mining Engineering, Industrial and ICT. \\ All the authors are from the Polytechnic University of Catalonia (UPC), Avenue Bases de Manresa, 61-73, \\ 08242-Manresa (Barcelona). \\ marc.bascompta@upc.edu; 1luis.sanmiquel@upc.edu; josep.oliva@upc.edu; hernan.anticoi@upc.edu; \\ eduard.guasch@upc.edu
}

\section{Extended Abstract}

Health and safety is a crucial issue in the mining industry because of the implication of fatalities in this sector. A study of safety culture maturity in several Latin America countries has been done based on the model from Filho et al. [1]. The questionnaire includes 28 items regarding the type of activity, number of employees and safety culture characteristics of the activity: Information of accidents and misses, organizational structure to deal with the information, involvement of the company in health and safety issues, the way it communicates accidents and misses and commitment of the company towards health and safety.

The questionnaire was completed by 58 mining company managers from Bolivia, Peru, Colombia and Mexico. Results show different behaviours depending on the type of company, cooperative or private company. When private companies are analysed, it is seen a level of maturity according to the size of the company, whereas cooperatives does not have a clear trend in terms of size apart from very small cooperatives, less than 10 employees. However, there is a remarkable difference between cooperatives that have implemented continuous improvement systems and the others. In particular, cooperatives with a continuous improvement system have been analysed, displaying much higher safety culture levels.

Therefore, it can be concluded that private companies improve their level of safety culture as the size of the company increase, because procedures and control systems are implemented. When cooperative or small companies introduce similar systems they also achieve substantial gains, but their approach is different. Managers from cooperatives have to see economic reasons to implement it, such as the Fairmined certificate.

\section{References}

[1] A. P. G. Filho, J. C. S. Andrade, and M. M. D. O. Marinho, "A safety culture maturity model for petrochemical companies in Brazil," Safety Science, vol. 48, no. 5, pp. 615-624, 2010. 